\title{
INNOVATION, KNOWLEDGE DIFFUSION, AND GLOBALIZATION
}

\author{
Nelson Lind \\ Natalia Ramondo \\ Working Paper 25071 \\ http://www.nber.org/papers/w25071
NATIONAL BUREAU OF ECONOMIC RESEARCH
1050 Massachusetts Avenue
Cambridge, MA 02138
September 2018

The views expressed herein are those of the authors and do not necessarily reflect the views of the National Bureau of Economic Research.

NBER working papers are circulated for discussion and comment purposes. They have not been peer-reviewed or been subject to the review by the NBER Board of Directors that accompanies official NBER publications.

(C) 2018 by Nelson Lind and Natalia Ramondo. All rights reserved. Short sections of text, not to exceed two paragraphs, may be quoted without explicit permission provided that full credit, including $(\odot$ notice, is given to the source. 
Innovation, Knowledge Diffusion, and Globalization

Nelson Lind and Natalia Ramondo

NBER Working Paper No. 25071

September 2018

JEL No. F1,O4

\begin{abstract}
$\underline{\text { ABSTRACT }}$
We review a recent body of theoretical literature that links the creation and diffusion of knowledge and technology to openness. We analyze two channels through which the spread of new ideas occurs: international trade and the activity of multinational firms (multinational production). The unifying theme of our survey is methodological. We focus on quantitative general equilibrium models that treat productivities as Fréchet random variables-as in the model of trade in Eaton and Kortum (2002) (EK). We present models in the literature that extend the EK model of trade to innovation, diffusion, and multinational firms, and examine the implications for counterfactuals related to the gains from trade. We finalize with new directions for research.
\end{abstract}

Nelson Lind

Department of Economics

Emory University

1602 Fishburne Drive

Rich Bldg., 3rd Floor

Atlanta, GA 30322-2240

nlind@emory.edu

Natalia Ramondo

School of Int'l Relations and Pacific Studies

University of California at San Diego

9500 Gilman Drive, MC 0519

La Jolla, CA 92093

and NBER

nramondo@ucsd.edu 


\section{Introduction}

A classic question in international economics has always been if-and how-openness increases the wealth of nations. A large part of the literature seeks to establish an empirical link between income and openness, while, simultaneously, a growing theoretical literature explores mechanisms through which openness increases income.

In this paper, we review the literature on quantitative general equilibrium models, spurred by Eaton and Kortum (2002) (EK), that link innovation and knowledge diffusion to international trade and the activity of multinational firms-what we call multinational production. In this context, globalization is broadly understood as openness to international trade, to MP, and to foreign ideas.

The unifying theme of our review is methodological. All the models reviewed are models that treat productivity as random draws from a Fréchet distribution. This treatment of productivities has been the transformative contribution of EK.

Given this organizing methodology, it is natural to start by analyzing growth models of innovation that generate Fréchet production possibilities frontiers. We present extensions of the EK model of trade that incorporate technology innovation through semiendogenous growth models (as in Jones, 1995; Kortum, 1997; Jones, 2005), and international technology diffusion (as in Eaton and Kortum, 2001, 1999). We review EK-type models in which trade is the channel for international diffusion and together they shape the gains from openness, as in Buera and Oberfield (2016). We then present extensions of the EK model of trade in which the channel for international technology diffusion is multinational production (MP), as introduced by Ramondo and Rodríguez-Clare (2013). Finally, we review recent research by Lind and Ramondo (2018) that generalizes the EK model of trade to capture spatial correlation of technologies. Their generalization encompasses most of the EK extensions in the literature and links to the innovation and diffusion models that generate Fréchet technology frontiers.

Different theories have been (fully and partially) motivated by the empirical evidence on international technology diffusion, and the role of international trade and MP as channels 
for technology transfer across countries. Most of the studies focus on outcomes such as productivity and income in receiving countries.

First, a large literature documents the link between growth and openness to trade. Crosscountry evidence suggests that more open economies have higher income levels and also they grow faster. Early evidence by Sachs and Warner (1995) shows that a group of eight always-open economies have consistently higher growth rates in the period 1965-1990 than forty always-closed economies. ${ }^{1}$ More recently, Alcala and Ciccone (2004) take into account the endogeneity of trade openness and estimate that the elasticity of productivity with respect to real openness is around 1.2, after controlling for quality of institutions, country size, and geography. ${ }^{2}$ More recent studies try to establish a causal link between openness and growth by appealing to natural experiments. In that regard, Feyrer (2009) uses the closure of the Suez Canal during the six-day war to establish the effect of distance on trade flows and of trade on income. Effects are large: A ten-percent decrease in ocean distance results in a five-percent increase in trade, and one more dollar of trade increases income by about 25 cents. Finally, a large set of papers, such as Pavcnik (2002), uses detailed firm-level data to document the effects of trade liberalization on industry productivity and turnover (see Harrison and Rodríguez-Clare, 2010, for a survey).

Second, a similarly large empirical literature documents how openness to foreign firms impacts receiving countries (see Harrison and Rodríguez-Clare, 2010; Keller, 2010; Antrás and Yeaple, 2014, for surveys). The basic premise is that MP is a channel through which new technology diffuses to firms in developing countries. The primary focus, as for trade flows, has been on the effect of Foreign Direct Investment (FDI) on the productivity of the receiving industries and domestic firms. Using firm-level data, the typical empirical tests revolve around measuring: the advantage of multinational firms, relative to domestic firms, in terms of firm outcomes such as productivity and revenues; and whether more exposure to foreign presence increases the productivity of domestic firms ("spillover"). ${ }^{3}$

\footnotetext{
${ }^{1}$ See also early work by Ades and Glaeser (1999), Frankel and Romer (1999), and Alesina et al. (2000) that find a significant effect of trade on productivity. See Donaldson (2015) for a survey.

${ }^{2}$ Real openness is measured as imports plus exports in exchange rate US dollars relative to GDP in purchasing power parity US dollars. Alcala and Ciccone (2004) argue that this is the correct measure of openness to be used.

${ }^{3}$ Ramondo (2009) and Alfaro and Chen (2018) also document the effects of foreign entry on the productivity distribution of the receiving industry through turnover of domestic firms-i.e., exit and entry.
} 
The firm-level evidence robustly finds that multinational firms perform better in several dimension than domestic firms. This result provides support to the hypothesis that multinational firms not only have better technologies, but they transfer them to their affiliates abroad, constituting a direct positive effect on the receiving industry. In contrast, the evidence on spillovers is mixed; robust findings are mostly related to vertical, not horizontal, linkages with domestic firms (see Javorcik, 2004).

Finally, the gains from globalization can materialize through direct international technology diffusion, allowing domestic firms to use foreign technologies. This flow is difficult to measure. As noticed by Ramondo et al. (2016), "except for the small part that happens through licensing, technology diffusion does not leave a paper trail that can be used to directly measure the value of production done in a country by domestic firms using foreign technologies." Some indirect evidence shows that international technology diffusion is responsible for most of the productivity growth in OECD countries, except for the United States (see Eaton and Kortum, 1996, 1999; Keller, 2004). Comin and Hobijn (2004) undertake a more direct effort to measure international technology diffusion and adoption patterns across countries and their link with income convergence. They build an impressive dataset that spans two centuries, covers as many as 166 countries-starting with 23 industrialized economies-and between 15 and 20 technologies belonging to textile production, steel manufacture, communications, information technology, transportation, and electricity. In this and subsequent papers (Comin and Hobijn, 2010; Comin et al., 2013; Comin and Mestieri, 2018), the authors document the characteristics and extent of international diffusion and adoption. The salient facts are: Most technologies originate in advanced economies, get adopted there first, and, subsequently, diffuse to countries that lag economically; newer technologies get adopted faster than older technologies; adoption rates are very heterogeneous across countries, even though adoption lags between rich and poor countries are narrower than in the past; differences in adoption rates account for at least 25 percent of per capita income differences; the degree of openness to trade is among the most important determinants of the speed of adoption; and finally, technology diffusion follows a spatial pattern with nearby countries experiencing higher They find that multinational entry increases the exit probability of domestic firms, but also increases the productivity of entrants. 
adoption rates of each other's technology.

\section{The Ricardian Model of Trade}

We now present the workhorse model of trade introduced by Eaton and Kortum (2002) (EK). Consider a global economy consisting of $N$ countries. Countries produce and trade in a continuum of product varieties $v \in[0,1]$. Consumers in all countries have identical constant-elasticity-of-substitution (CES) preferences with elasticity of substitution $\sigma>0$ : $C_{d}=\left(\int_{0}^{1} C_{d}(v)^{(\sigma-1) / \sigma} \mathrm{d} v\right)^{\sigma /(\sigma-1)}$. Expenditure by destination $d$ on variety $v$ is $X_{d}(v) \equiv$ $P_{d}(v) C_{d}(v)=\left(P_{d}(v) / P_{d}\right)^{1-\sigma} X_{d}$ where $P_{d}(v)$ is the cost of the variety in terms of numeraire, $P_{d}=\left(\int_{0}^{1} P_{d}(v)^{1-\sigma} \mathrm{d} v\right)^{\frac{1}{1-\sigma}}$ is the price level in country $d$, and $X_{d}=P_{d} C_{d}$ is the country's total expenditure.

We assume that the production function for varieties presents constant returns to scale in labor and depends on the origin country $o$ where the good gets produced. For each $v \in[0,1]$, output $Y_{o}(v)$ satisfies

$$
Y_{o}(v)=A_{o}(v) L_{o}(v)
$$

where $L_{o}(v)$ is the amount of labor used to produce variety $v$ at origin $o$ and $A_{o}(v)$ is the marginal product of labor-referred as productivity.

Suppose that to ship goods from country o to $d$ there is an iceberg-type $\operatorname{cost} \tau_{o d} \geq 1$ : Firms from $o$ need to ship $\tau_{o d}$ units of the good for one unit to arrive to $d$. Additionally, the usual triangular inequality is satisfied, for any $o, d$, and $n, \tau_{o n} \tau_{n d}>\tau_{o d}$, and trade is frictionless within a country, $\tau_{d d}=1$.

The marginal cost to deliver good $v$ to destination $d$ from origin $o$ is then

$$
c_{o d}(v)=\tau_{o d} \frac{W_{o}}{A_{o}(v)}
$$

where $W_{o}$ is the nominal wage in country $o$. As in the original model, we assume perfect competition so that prices are equal to unit costs, $P_{o d}(v)=c_{o d}(v)$. Good $v$ is provided to 
country $d$ by the cheapest supplier,

$$
P_{d}(v)=\min _{o=1, \ldots, N} \tau_{o d} \frac{W_{o}}{A_{o}(v)} .
$$

Heterogeneity in production possibilities is captured by modeling productivity $A_{o}(v)$ as a random draw. EK assume that productivity is a Fréchet random variable, independent both across the continuum of goods and across exporters. The joint distribution of productivity across countries is

$$
\mathbb{P}\left[A_{1}(v) \leq a_{1}, \ldots, A_{o}(v) \leq a_{N}\right]=\prod_{o=1, \ldots, N} \mathbb{P}\left[A_{o}(v) \leq a_{o}\right]=\exp \left(-\sum_{o=1}^{N} T_{o} a_{o}^{-\theta}\right),
$$

where $T_{o}>0$ is the scale parameter for origin $o$ and $\theta>0$ is a common shape parameter. A higher scale parameter $T_{o}$ means that a country has on average better productivity draws (i.e., larger $T$ 's increases the probability of larger values of $A_{o}(v)$ ), capturing aggregate productivity of country o (i.e., its absolute advantage). A higher shape parameter $\theta$ means less heterogeneity in productivity draws across the continuum of goods (within each origin), whereby capturing relative productivities differences (i.e., comparative advantage).

Under independent Fréchet with a common shape parameter, tractability is achieved thanks to a property known as max stability: The Fréchet distribution is preserved under the maximum operator,

$$
\mathbb{P}\left[\max _{o=1, \ldots, N} A_{o}(v) \leq a\right]=\prod_{o=1, \ldots, N} \mathbb{P}\left[A_{o}(v) \leq a\right]=\exp \left[-\left(\sum_{o=1}^{N} T_{o}\right) a^{-\theta}\right] .
$$

This max-stability property is key for deriving equilibrium prices and bilateral trade shares in closed form.

In particular, the joint distribution of productivity determines the joint distribution of potential import prices. Using (2), the distribution of potential import prices into a desti- 
nation country $d$ is given by

$$
\mathbb{P}\left[P_{1 d}(v) \leq p_{1}, \ldots, P_{N d}(v) \leq p_{N}\right]=\prod_{o=1, \ldots, N} \mathbb{P}\left[P_{o d}(v) \leq p_{o}\right]=\prod_{o=1, \ldots, N}\left[1-\exp \left(-\phi_{o d} p_{o}^{\theta},\right)\right]
$$

where $\phi_{o d} \equiv T_{o}\left(\tau_{o d} W_{o}\right)^{-\theta}$. For each origin $o$, the marginal distribution of prices, $\mathbb{P}\left[P_{o d}(v) \leq\right.$ $p]=1-\exp \left[-\phi_{o d} p^{\theta}\right]$, is a Weibull distribution with scale parameter $\phi_{o d}$ and shape parameter $\theta$.

Using (6), we derive the distribution of prices actually paid by consumers in $d$,

$$
\mathbb{P}\left[\min _{o^{\prime}} P_{o^{\prime} d}(v) \leq p\right]=1-\mathbb{P}\left[\min _{o^{\prime}} P_{o^{\prime} d}(v)>p\right]=1-\prod_{o=1, \ldots, N} \exp \left(\phi_{o d} p^{\theta}\right)=1-\exp \left(-\Phi_{d} p^{\theta}\right)
$$

The scale is $\Phi_{d} \equiv \sum_{o} \phi_{o d}$ and the shape is $\theta$. The shape parameter indicates the price dispersion across the continuum of goods, while the scale summarizes the overall level of prices in the destination market. This variable indicates how easy it is to access market $d$ because it determines the overall price index in the destination market.

Using (7), the CES price index in country $d$ is calculated as the following expected value

$$
P_{d}=\mathbb{E}\left[\min _{o=1, \ldots, N} P_{o d}(v)^{1-\sigma}\right]^{\frac{1}{1-\sigma}}=\gamma \Phi_{d}^{-\frac{1}{\theta}}
$$

where $\gamma \equiv \Gamma\left(\frac{\theta+1-\sigma}{\theta}\right)^{\frac{1}{1-\sigma}}$ and $\Gamma(\cdot)$ is the Gamma function. This expression tells us that: Countries that are easy to access (i.e., lower $\Phi_{d}$ ) have lower prices on average; in autarky (i.e., $\tau_{o d}=\infty$ for all $o \neq d$ ), prices are the highest and equal to $P_{d}=\gamma A_{d}^{-\frac{1}{\theta}} W_{d}$; and in a frictionless world (i.e., $\tau_{o d}=1$, for all $o, d$ ), the law of price holds with $\Phi_{d}=\Phi$, for all $d$.

Given the distribution of prices, we can also solve for the fraction of goods that destination $d$ imports from source $o$. Because draws across goods are i.i.d. and there is a continuum of goods, by the law of large numbers, the fraction of goods imported from $o$ into $d$ is equal to the probability that country $o$ is the lowest-cost producer of good $v$ to destination $d$,

$$
\pi_{o d} \equiv \mathbb{P}\left[P_{o d}(v) \leq \min _{o^{\prime} \neq o} P_{o^{\prime} d}(v)\right]=\frac{T_{o}\left(\tau_{o d} W_{o}\right)^{-\theta}}{\sum_{o^{\prime}} T_{o^{\prime}}\left(\tau_{o^{\prime} d} W_{o^{\prime}}\right)^{-\theta}}
$$


The lower bilateral trade $\operatorname{costs} \tau_{o d}$, and the higher source productivity $T_{o}$, relative to all other sources, the larger the fraction of goods that country $o$ imports into $d$.

The probability in (9) coincides with the share of expenditure of $d$ on goods from $o$ due to a key feature of the EK model: The distribution of prices among goods sold in a destination is equal to the distribution of prices among goods sold by any source to the destination. This result is a consequence of the max-stability property of the $\theta$-Fréchet distribution which implies that the conditional and unconditional distribution of the maximum (minimum) are identical. This translates into identical distribution of prices in $d$ unconditional and conditional on a source $o$ being the lowest-cost producer for $d$,

$$
\mathbb{P}\left[\min _{o^{\prime}=1, \ldots, N} P_{o^{\prime} d}(v) \leq p\right]=\mathbb{P}\left[P_{o d}(v) \leq p \mid P_{o d}(v)=\min _{o^{\prime}=1, \ldots, N} P_{o^{\prime} d}(v)\right] .
$$

Intuitively, origins with better comparative advantage (i.e., lower trade costs, better productivity, or lower labor costs) in serving $d$ sell more goods to $d$ exactly to the point where the distribution of prices of their goods sold to $d$ is the same as the overall price distribution in $d$.

Because the conditional and unconditional maximum distributions coincide, the share of total expenditure in country $d$ devoted to goods from country o is equal to the fraction of goods imported from o into $d$,

$$
X_{o d}=\pi_{o d} X_{d}
$$

Intuitively, the distribution of prices across goods imported into country $d$ are the same regardless of their source, so it is only the probability of being the lowest cost source that matters.

Combining (9) with (10), we see that expenditure is a CES import demand system with elasticity of substitution $\theta$. As a result, in the words of Arkolakis et al. (2012), it constitutes a gravity system since it can be expressed as a log-linear function of two set of country effects and a bilateral term,

$$
\ln X_{o d}=S_{o}+D_{d}-\theta \ln \tau_{o d}
$$


where $S_{o} \equiv \ln T_{o} W_{o}^{-\theta}$ and $D_{d}=\ln X_{d} \gamma P_{d}^{\theta}$.

Finally, as shown in Arkolakis et al. (2008) and Arkolakis et al. (2012), the real wage in country $d$ can be written as

$$
\frac{W_{d}}{P_{d}}=\gamma^{-1} \times T_{d}^{1 / \theta} \times \pi_{d d}^{-1 / \theta} .
$$

We refer to the share of goods that a country imports $1-\pi_{d d}$ as its openness. This equation states that real per-capita income for a country is given by its degree of openness and by its average productivity level. The influence of both openness and average productivity on welfare is governed by the same parameter, $\theta$.

In autarky, the real wage is simply

$$
\frac{W_{d}^{\text {aut }}}{P_{d}^{\text {aut }}}=\gamma^{-1} T_{d}^{1 / \theta}
$$

so that the gains from trade for country $d$, defined as the change in real wages from autarky to the actual equilibrium is

$$
G T_{d}=\pi_{d d}^{-1 / \theta}
$$

The gains from trade are positively related to the degree of openness.

Further assuming, as in Ramondo et al. (2016), that average productivity in a country is proportional to the country's size yields

$$
T_{o}=r_{o} L_{o}
$$

This expression, together with (12) and (14), makes clear that the forces that shape the gains from trade in EK-type trade models-and more generally, in the class of CES models studied in ACR-are the same forces that shape the aggregate scale effects present in closed-economy semi-endogenous growth models (Jones, 1995; Kortum, 1997). Conditional on openness, average real income levels increase in country size with an elasticity of $1 / \theta$.

The parameter $\theta$ is key in several dimension: it captures the degree of productivity dispersion across goods, equals the elasticity of trade expenditure to trade costs, and determines 
both the sensitivity of the gains from trade to openness and of income to scale effects. For instance, a lower $\theta$ indicates more heterogeneity, stronger comparative advantage forces, and stronger effects of size and openness, respectively, on income.

The expression in (15) links a larger population to the scale parameter of the Fréchet distribution. The strength of the link between income and the creation of (non-rival) ideas is regulated by the shape parameter of the Fréchet distribution. Next, we turn to innovation and diffusion models that generate production possibility frontiers that are Fréchet.

\section{Innovation and Diffusion in the Ricardian Model of Trade}

In this section, we review the literature that adds knowledge creation and diffusion to the EK model of trade. First, we show how the literature has gone about generating production possibility frontiers that are Fréchet, following the work by Kortum (1997). Second, we present an EK-type model of trade based on Buera and Oberfield (2016) in which international diffusion of knowledge occurs through trade. Finally, we present the extension of the EK model of trade to multinational production (MP) in Ramondo and Rodríguez-Clare (2013) in which diffusion of knowledge occurs through the activities of multinational firms.

\subsection{Fréchet as a result of innovation}

We showed in the previous section that, due to the max-stability property, the Fréchet distribution is the "right" distribution to solve Ricardian-type models in closed form. This is because the key feature of these models is a head-to-head comparison of unit costs across producers of the same good for destination market $d$. But what economic justification underlies the Fréchet assumption?

The basic idea was introduced in Kortum (1997). He shows that if the production technology is determined by the best "idea", or blueprint, and if ideas become available according to a Poisson process, then after a sufficiently long period of time productivity can 
be approximated by an extreme value distribution. ${ }^{4}$

For illustration purposes, suppose that the number of ideas available for producing a good is $k$. Assume that the productivity of each idea is drawn i.i.d. from a distribution $H(a)=\mathbb{P}\left[A_{i} \leq a\right]$, which we refer to as the exogenous distribution of ideas. Consider the productivity of the most efficient idea: $A_{k}^{*}=\max \left\{A_{1}, \ldots, A_{k}\right\}$. Then the distribution of the maximum is $\mathbb{P}\left[A_{k}^{*} \leq a\right]=H(a)^{k}$. By standard results from extreme value theory (de Haan and Ferreira, 2006), if a limiting normalized distribution exists as $k \rightarrow \infty$, it must be an extreme value distribution: Gumbel, Fréchet, or Weibull.

One important insight from Kortum (1997) is that the limiting distribution remains within the extreme value family if the number of ideas available is itself a Poisson random variable $K$ with average number of innovations $T$ 一so that $\mathbb{P}[K=k]=\frac{e^{-T} T^{k}}{k !}$. In this case, the productivity distribution of the best idea has a closed form,

$$
\mathbb{P}\left[A_{K}^{*}<a\right]=\sum_{k=0}^{\infty} \mathbb{P}[K=k] \mathbb{P}\left[A_{K}^{*} \leq a \mid K=k\right]=\sum_{k=0}^{\infty} \frac{e^{-T} T^{k}}{k !} H(a)^{k}=e^{-T[1-H(a)]}
$$

The productivity distribution across adopted innovations reflects the average number of innovations, $T$, and the distribution of productivity across all innovations. The results in Kortum (1997) arise because, as the scale parameter of the Poisson process gets large, most goods have many innovations and the distribution converges to an extreme value distribution. The specific limiting distribution depends on the properties of the innovation distribution, $H$. For example, a Fréchet distribution arises if the distribution of productivity across innovations has a Pareto right tail, as specified in Assumption 1.

Assumption 1 (Pareto-Tailed Exogenous Distribution of Ideas). There exists $\theta>0$ such that

$$
\lim _{a \rightarrow \infty} \frac{1-H(a)}{a^{-\theta}}=1
$$

Under this assumption, for sufficiently large $T$, the productivity distribution is approxi-

\footnotetext{
${ }^{4}$ There is a relatively large literature that models innovation and diffusion of technologies as stochastic processes in closed economy setups, starting by the early work of Jovanovic and McDonald (1994) and Jovanovic and Rob (1989), followed by Eeckhout and Jovanovic (2002), Alvarez et al. (2008), Lucas (2009), Luttmer (2012), Lucas and Moll (2014), Perla and Tonetti (2014), and Benhabib et al. (2017), among others.
} 
mately Fréchet, as in (4),

$$
\lim _{T \rightarrow \infty} \mathbb{P}\left[A_{K}^{*}<T^{1 / \theta} z\right]=\lim _{T \rightarrow \infty} e^{-T\left[1-H\left(T^{1 / \theta} z\right)\right]}=\lim _{a \rightarrow \infty} e^{-z^{-\theta} \frac{1-H(a)}{a^{-\theta}}}=e^{-z^{-\theta}} .
$$

This result links EK-type models of trade to models of innovation.

For example, Eaton and Kortum (2001) develop a model of trade based on this result for the special case of Pareto innovations: $H(a)=1-a^{-\theta}$, for $a \geq 1$. Researchers in country $o$ draws ideas independently across countries at a Poisson rate $r_{o}$ with ideas distributed uniformly across goods. The distribution of innovations across varieties is then independent across countries and Poisson with the average number of innovations determined by accumulated research, $T_{o t}=r_{o} \int_{0}^{t} L_{o}(s) \mathrm{d} s$. Applying the previous result, if $T_{o t} \rightarrow \infty$ as $t \rightarrow \infty$, the distribution of productivity within each country is asymptotically Fréchet and independent across countries. ${ }^{5}$

Building on the idea in Kortum (1997) for a closed economy, Eaton and Kortum (1999) present a model in which ideas diffuse across countries and in each country the distribution of productivities is Fréchet. In this model, however, the international diffusion of ideas occurs at exogenous rates, and countries are otherwise in autarky. That is, international trade is not a channel through which ideas get diffused, or diffusion accelerates; international trade and international diffusion are substitutes. ${ }^{6}$

\subsection{Diffusion through trade}

As documented by Comin et al. (2013), international diffusion, however, follows a spatial pattern that may be linked to trade and other international flows such as the activity of multinational firms (as implied by the empirical exercises in Keller and Yeaple, 2013; Irarrazabal et al., 2013). In this spirit, there is a set of papers that propose models in which trade shapes the ideas to which people are exposed (see Alvarez et al., 2014; Perla et al.,

\footnotetext{
${ }^{5}$ A sufficient condition for $T_{o t} \rightarrow \infty$ as $t \rightarrow \infty$ is that $L_{o}(t) \geq \underline{L}_{o}>0$, for all $t$.

${ }^{6}$ In the same spirit, Rodríguez-Clare (2007) incorporates diffusion into the EK model of trade. As in Eaton and Kortum (1999), trade and diffusion are substitutes and any complementarity between them is ruled out. A similar approach is taken in Ramondo and Rodríguez-Clare (2010) who further enlarge the model in Rodríguez-Clare (2007) to also incorporate MP in ways explained below.
} 
2015; Sampson, 2016).

We focus here in a recent paper by Buera and Oberfield (2016) which incorporates innovation and international diffusion into an EK-type model, but, crucially, international diffusion happens because of international trade. ${ }^{7}$ Their model belongs to the class of models that generate a Fréchet production possibility frontier for each country. Moreover, the model delivers a simple system of differential equations for the evolution of the country's stock of knowledge-the scale parameters of the Fréchet distributions.

Assume that for each good there are $M$ competitive firms within each country. ${ }^{8}$ For each firm $m$, and time $t$, the production function for good $v$ is the same as in (1) and marginal cost is the same as in (2). Perfect competition implies that in each country $o$ the firm with the lowest marginal cost produces good $v$. The frontier of knowledge in $o$ for producing $v$ is then given by the productivity of the most efficient firm, $A_{o t}(v) \equiv \max _{m=1, \ldots, M} A_{m o t}(v)$.

Provided that $A_{m o t}(v)$ is independent across $m$ within $o$, the frontier distribution of productivity is

$$
\tilde{F}_{o t}(a)=\mathbb{P}\left[A_{m o t}(v) \leq a\right]^{M} .
$$

This distribution is the result of taking the maximum of i.i.d. random variables. As we explained in Section 3.1, if the distribution converges as $M \rightarrow \infty$ (with an appropriate normalization), then it must converge to an extreme value distribution.

Assume that firms within origin $o$ draw insights independently at a Poisson rate $r_{o t}$. These insights may come from firms worldwide. The distribution of productivity from which ideas are drawn, the source distribution, is $\tilde{F}_{o t}^{*}(a)$. To start, we take this distribution as exogenous. When an idea arrives to a firm, it has productivity $z\left(a^{\prime}\right)^{\beta}$. The component $a^{\prime}$ is drawn from the source distribution and captures learning from others. The parameter $\beta$ controls the degree of diminishing returns in the adoption of ideas. The component $z$ is drawn from a time-invariant distribution $H$, the exogenous distribution of ideas, and

\footnotetext{
${ }^{7}$ Recent examples of models of innovation in open economies are Atkeson and Burstein (2010), which use a Melitz dynamic model with an entry stage augmented by a stochastic innovation process, and Somale (2018), who extends the static trade model in Bernard et al. (2003) to a multi-sector semi-endogenous growth model in which innovation efforts can be directed to specific industries.

${ }^{8}$ Buera and Oberfield (2016) assume Bertrand competition among firms. For simplicity, we assume perfect competition and end up with the same aggregate implications.
} 
represents randomness in adapting the idea.

A firm with original productivity $a$ adopts the idea if it increases its productivity, $z\left(a^{\prime}\right)^{\beta}>$ a. As a result, for a small time increment $\Delta>0$,

$$
\mathbb{P}\left[A_{m, o, t+\Delta}(v) \leq a\right]=\mathbb{P}\left[A_{m o t}(v) \leq a\right]\left[\left(1-r_{o t} \Delta\right)+r_{o t} \Delta \int_{0}^{\infty} H\left(a / x^{\beta}\right) \mathrm{d} \tilde{F}_{o t}^{*}(x)\right]
$$

so that the frontier distribution evolves as

$$
\begin{aligned}
\frac{\partial}{\partial t} \ln \tilde{F}_{o t}(a)=M \frac{\partial}{\partial t} \ln \mathbb{P}\left[A_{m o t}(v) \leq a\right] & =M \lim _{\Delta \rightarrow 0} \frac{\mathbb{P}\left[A_{m, o, t+\Delta}(v) \leq a\right]-\mathbb{P}\left[A_{m o t}(v) \leq a\right]}{\Delta \mathbb{P}\left[A_{m o t}(v) \leq a\right]} \\
& =-M r_{o t} \int_{0}^{\infty}\left[1-H\left(a / x^{\beta}\right)\right] \mathrm{d} \tilde{F}_{o t}^{*}(x) .
\end{aligned}
$$

The evolution of the frontier distribution in any given origin depends on the rate at which ideas diffuse to firms and the source distribution from which firms draw ideas.

We get a Fréchet frontier distribution for productivity in each origin by considering the limiting case of this economy as $M \rightarrow \infty$. We need the two following assumptions in addition to Assumption 1.

Assumption 2 (Diminishing Returns to Learning). $\beta \in[0,1)$.

Assumption 3 (Thin-Tail Source Distribution). At each $t, \lim _{a \rightarrow \infty} a^{\beta \theta}\left[1-\tilde{F}_{o t}^{*}(a)\right]=0$.

The assumption of diminishing returns implies that the model generates semi-endogenous growth. The second assumption is a regularity assumption that ensures that growth in the frontier distribution of productivity remains finite at each point in time. ${ }^{9}$ Later, when the source distribution is endogenized, we replace Assumption 3 with an analogous restriction on the initial frontier distribution in each country.

Similar to the approach in Section 3.1, we scale the frontier distribution of productivity by $M^{\frac{1}{(1-\beta) \theta}}$, and define $F_{o t}(a) \equiv \mathbb{P}\left[M^{-\frac{1}{(1-\beta) \theta}} A_{o t}(v) \leq a\right]=\tilde{F}_{o t}\left(M^{\frac{1}{(1-\beta) \theta}} a\right)$, and $F_{o t}^{*}(a) \equiv$ $\tilde{F}_{o t}^{*}\left(M^{\frac{1}{(1-\beta) \theta}} a\right)$. Changing variables yields

$$
\frac{\partial}{\partial t} \ln F_{o t}(a)=-r_{o t} a^{-\theta} \int_{0}^{\infty}\left[\frac{1-H\left(M^{1 / \theta} a x^{\beta}\right)}{\left(M^{1 / \theta} a x^{-\beta}\right)^{-\theta}}\right] x^{\beta \theta} \mathrm{d} F_{o t}^{*}(x) .
$$

\footnotetext{
${ }^{9}$ For example, a bounded distribution would satisfy Assumption 3.
} 
As $M \rightarrow \infty$, due to the dominated convergence theorem, the limiting case is given by

$$
\frac{\partial}{\partial t} \ln F_{o t}(a)=-r_{o t} a^{-\theta} \int_{0}^{\infty} x^{\beta \theta} \mathrm{d} F_{o t}^{*}(x)
$$

For any fixed $a$ and initial $F_{o 0}(a)$, this equation is a differential equation with solution

$$
F_{o t}(a)=F_{o 0}(a) e^{-\left(T_{o t}-T_{o 0}\right) a^{-\theta}} \quad \text { where } \quad T_{o t} \equiv \int_{-\infty}^{t} r_{o s} \int_{0}^{\infty} x^{\beta \theta} \mathrm{d} F_{o s}^{*}(x) \mathrm{d} s .
$$

One can immediately see that if the initial knowledge frontier is Fréchet with scale $T_{o 0}$ and shape $\theta$, then the distribution at $t$ is also Fréchet with the same shape, $F_{o t}(a)=e^{-T_{o t} a^{-\theta}}$. Additionally, the evolution of the scale parameter $T_{o t}$ reflects the Poisson rate at which ideas diffuse into country $o$ and the source distribution of productivity from which ideas are drawn,

$$
\frac{\partial}{\partial t} T_{o t}=r_{o t} \int_{0}^{\infty} x^{\beta \theta} \mathrm{d} F_{o t}^{*}(x)
$$

This model of knowledge diffusion implies that at any point in time productivity is distributed independently Fréchet across countries with a common shape parameter. As a result, the static trade theory is identical to the EK model of trade in Section 2.

To examine the implications of the static trade equilibrium for the dynamics of knowledge diffusion, we next endogenize the source distribution of productivity. We focus on a specification in which domestic firms can learn-and adapt ideas-from those firms in the global economy which sell goods in $o^{10}$ The source distribution of productivity in country $o$ is given by

$$
\tilde{F}_{o t}^{*}(a)=\sum_{o^{\prime}=1}^{N} \int_{\left\{v \in V_{o^{\prime} o t} \mid A_{o^{\prime} t}(v) \leq a\right\}} \mathrm{d} v
$$

where $V_{o^{\prime} o t}$ is the set of varieties produced in $o^{\prime}$ and sold in $o$ at time $t$. International trade matters for the evolution of the frontier productivity distribution because access to new ideas depends on which firms sell in the domestic market.

Given the endogeneity of the source distribution, Assumption 3 has to be replaced by the following condition on the initial frontier of knowledge in each country.

\footnotetext{
${ }^{10}$ This assumption is as in Alvarez et al. (2014).
} 
Assumption 4 (Thin-Tail Initial Distribution). $\forall o=1, \ldots, N, \lim _{a \rightarrow \infty} a^{\beta \theta}\left[1-\tilde{F}_{o 0}(a)\right]=0$

Buera and Oberfield (2016) show that, in the case of an endogenous source distribution as in (17), Assumption 3 is the result of this assumption on the initial distribution, and hence, the results derived for an exogenous source distribution go through. In particular, the law of motion for the scale parameter $T_{o t}$ in (16) specializes to

$$
\frac{\partial}{\partial t} T_{o t}=\Gamma(1-\beta) \times r_{o t} \times \sum_{o^{\prime}=1}^{N} \pi_{o^{\prime} o t} T_{o^{\prime} t} \times \pi_{o^{\prime} o t}^{-\beta}
$$

where $\Gamma(\cdot)$ is the Gamma function. Aggregate productivity growth in country $o$ depends on the exogenous rate at which domestic firms draw ideas, $r_{o t}$, as well as an expenditureweighted average of the productivity of each of its trading partners. Trade influences the diffusion of knowledge through two channels. The first channel is captured by the term $\pi_{o^{\prime} o t} T_{o^{\prime} t}$ : International competition increases productivity growth because trade allows for more productive foreign firms to sell in the domestic market. When a country lowers its trade barriers, low-productivity domestic producers lose market share to highproductivity foreign producers. As a result, freer trade improves the average productivity of the set of firms selling in the domestic market, which means faster learning and higher growth. The second channel, captured by the term $\pi_{o^{\prime} o t}^{-\beta}$ is an offsetting selection effect: with low trade barriers, many low productivity foreign firms can compete in the domestic market. As trade barriers on foreign country $o^{\prime}$ fall, the expenditure share $\pi_{o^{\prime} o t}$ increases and selection toward low-productivity foreign firms dampens learning and growth.

An important implication of these two offsetting effects is that growth is not necessarily maximized at free trade. Rather, growth is maximized when trade is biased towards those foreign countries with better technology than the domestic country. Buera and Oberfield (2016) show that this maximum is achieved by choosing relative trade barriers proportional to wage differences across trading partners. Intuitively, average productivity is high among firms in countries with high wages. Hence, tilting trade barriers to increase trade with high wage countries will lead to more rapid diffusion of knowledge and higher growth.

What are the gains from trade after accounting for trade-induced knowledge diffusion? 
Since the import demand system is CES, the results of Arkolakis et al. (2012) apply: A country's real wage, at each time $t$, is given by the expression in (12), and the static gains from trade (holding fixed $T_{o t}$ ) are as in (24). ${ }^{11}$

To gain intuition for the dynamic gains from trade, we consider the case of a symmetric world economy with cross-country trade barriers $\tau \geq 1$ and within country trade barriers equal to one. In this case, each country's self-trade share is constant, $\pi_{D}=$ $\left(1+(N-1) \tau^{-\theta}\right)^{-1}$, and the import trade share with each partner is $\pi_{F}=\left(1-\pi_{D}\right) /(N-1)$. Additionally, in order to incorporate exogenous growth of the global economy, assume that the arrival rate of ideas grows over time at rate $\gamma$. Let $\hat{T}_{t} \equiv T_{0} e^{-\frac{\gamma}{1-\beta} t}$ denote detrended productivity and, analogously, $\hat{r}_{t} \equiv r_{t} e^{-\frac{\gamma}{1-\beta} t}$. On a balanced growth path-i.e., constant $\hat{r}_{t}$-the evolution over time of aggregate (de-trended) productivity is given by

$$
\frac{\partial}{\partial t} \hat{T}_{t}=\tilde{\gamma}^{1-\beta} \times \hat{r}_{t} \times N \times \pi_{D}^{1-\beta} \times \hat{T}_{t}^{\beta} \quad, \quad \tilde{\gamma}>0,{ }^{12}
$$

which implies that along a balanced growth path aggregate (de-trended) productivity is constant,

$$
\hat{T}=\tilde{\gamma} \times \hat{r}^{\frac{1}{1-\beta}} \times\left[\pi_{D}^{1-\beta}+(N-1) \pi_{F}^{1-\beta}\right]^{\frac{1}{1-\beta}} .
$$

The dynamic gains from trade, which incorporate the difference in productivity relative to autarky along a balanced-growth path (BGP), are then

$$
G T^{B G P}=\pi_{D}^{-\frac{1}{\theta}} \times\left[\pi_{D}^{1-\beta}+(N-1) \pi_{F}^{1-\beta}\right]^{\frac{1}{\theta(1-\beta)}} \cdot \cdot^{13}
$$

While the first term represents the static gains from trade, as in Arkolakis et al. (2012), the second term captures the dynamic effect of knowledge diffusion and learning. When there is no learning $(\beta=0)$, the model collapses to $\mathrm{EK}$, and the dynamic gains from trade coincide with the static gains from trade. For $\beta>0$, the increase in aggregate productivity depends on the degree of openness of the economy: As a country opens up to trade, it gains opportunities to learn from foreign firms and the productivity of their domestic

\footnotetext{
${ }^{11}$ The counterfactual here is one in which a country has a current self-trade share of $\pi_{d d t}=\pi_{d d}$ and moves to autarky for a single moment.

$12 \tilde{\gamma} \equiv[(1-\beta) \Gamma(1-\beta) / \gamma]^{1 /(1-\beta)}$.

${ }^{13}$ These are the gains from trade coming from a unilateral move to autarky.
} 
firms increases. As the force of diminishing returns in learning weakens ( $\beta$ increases), the effect is magnified, and the dynamic part of the gains from trade becomes more and more important.

Buera and Oberfield (2016) consider an alternative way of endogenizing the source distribution of productivity: Domestic firms learn from other domestic producers rather than from world-wide sellers. ${ }^{14}$ In this case, the source distribution of productivity in country $o$ is specified as

$$
\tilde{F}_{o t}^{*}(a)=\frac{\int_{v \in V_{o o t} \mid A_{o t}(v) \leq a} \mathrm{~d} v}{\int_{v \in V_{o o t}} \mathrm{~d} v},
$$

where $V_{\text {oot }}$ is the set of varieties produced and sold in $o$ at time $t$. Following the derivations in Buera and Oberfield (2016) and specializing (16) to the source distribution in (18) delivers

$$
\frac{\partial}{\partial t} T_{o t}=\Gamma(1-\beta) \times r_{o t} \times T_{o t}^{\beta} \times \pi_{o o}^{-\beta} .
$$

Trade increases a country's stock of knowledge because as a country opens up to trade, unproductive technologies are selected out and more productive domestic producers survive. This raises the average quality of idea draws and increases the growth rate of the stock of knowledge.

As in the case in which learning occurs through global sellers, the dynamic gains from trade consider not only the static gains from trade but also the gains coming from the changes in the stock of knowledge due to diffusion. In a symmetric world, the de-trended aggregate productivity in a balance growth path is simply

$$
\hat{T}=\tilde{\gamma} \times \hat{r}^{\frac{1}{1-\beta}} \times \pi_{D}^{-\frac{\beta}{1-\beta}},
$$

so that the gains from trade in a balance growth path are

$$
G T^{B G P}=\pi_{D}^{-\frac{\beta}{1-\beta} \frac{1}{\theta}} .
$$

As for the case of a source distribution in which domestic firm learn from world-wide sellers, with no learning $\beta=0$, the dynamic and static gains from trade coincide. For $\beta>0$,

\footnotetext{
${ }^{14}$ This treatment is similar to the one in Perla et al. (2015) and Sampson (2016).
} 
learning opportunities increase with openness due to the selection effect on unproductive domestic producers, with a larger effect as $\beta$ increases.

The model developed in Buera and Oberfield (2016) constitutes a parsimonious, yet quantitative, theory in which diffusion and international trade interact to shape the gains from openness. As all the models we review, the Fréchet productivity distribution is at the center of their analysis.

\subsection{Diffusion through multinational production}

Multinational production (MP) is arguably the most important channel through which firms choose to serve foreign consumers. ${ }^{15}$ As documented by UNCTAD (2017), in 2016, world sales of foreign affiliates of multinational firms were almost twice as high as world exports, with an increase over the past two decades of a factor of more than six against a factor of almost four for exports. Additionally, according to the Bureau of Economic Analysis (BEA), foreign affiliates of U.S. MNEs accounted, in 2009, for 75 percent of U.S. sales to foreign customers; the remaining 25 percent was filled by U.S. exports.

Multinational firms also are, not surprisingly, the top innovators of the world. UNCTAD (2005) estimates that multinational firms concentrated close to half of the world R\&D expenditure, and at least two-thirds of business R\&D expenditures, at the beginning of the 2000's. The link between R\&D and MP activity is also documented by Arkolakis et al. (2018) who show that the most innovative OECD economies, measured by R\&D expenditures in manufacturing relative to local value-added, are also the ones with net outward MP flows (measured by the sales of foreign affiliates of Home firm minus the sales of foreign multinational affiliates at Home). ${ }^{16}$

Both the macro and micro evidence suggests that MP is an important channel through

\footnotetext{
${ }^{15}$ We follow Ramondo (2014) and use the term "multinational production", rather than "Foreign Direct Investment" (FDI) to refer to the activity of foreign affiliates (e.g., sales, employment). FDI is a financial category of the Balance of Payments and, as such, is one of the possible channels through which affiliates finance their activities abroad.

${ }^{16}$ Arkolakis et al. (2018) document a similar positive correlation for the United States across time: R\&D expenditures relative to manufacturing value-added in the United States grew from 8.7 to 12.7 percent between 1999 and 2009, while at the same time, U.S. multinational firms increased the share of employment located in their foreign affiliates from 22 to 31 percent.
} 
which countries exchange not only goods, but also ideas and technologies, and as such, it may lead to large gains from international technology sharing.

The idea of MP as a channel for international technology diffusion was present in early work by Markusen (1984): His concept of "knowledge capital" entailed the idea that this type of capital was freely shared within different units of the firm, at Home and abroad. Building on the idea of non-rivalry, more recent papers develop and quantify models in which international technology diffusion occurs through MP. Using a neoclassical growth model, McGrattan and Prescott (2009) pair MP with the transfer (and reproduction) of firm-specific technology capital in foreign countries. ${ }^{17}$ They calculate (steady state) gains from MP (from autarky) of 27 percent of real consumption, for a small country, and of one percent for a large country. Ramondo (2014) uses an EK-type framework in which MP is paired with the (costly) transfer of home technologies abroad. She calculates gains from MP (from autarky) of almost nine percent of real per capita income. Irarrazabal et al. (2013) extend the proximity-concentration tradeoff framework in Helpman et al. (2004) to incorporate intrafirm transfers of firm-specific inputs, both tangible and intangible. Using firm-level data for Norway, they estimate that the share of a parent's input costs in the affiliate total costs is substantial (9/10). Similarly, Shikher (2012) and Ramondo and Rodríguez-Clare (2013) also pair MP with the international transfer of technologies for production abroad. Their model incorporates both trade and MP into an EK-type model with the goal of quantifying the gains from trade and MP. In particular, Ramondo and Rodríguez-Clare (2013) extend the probabilistic representation of technologies introduced by EK, and show that their framework is consistent with the growth models in Section 3.1 that generate a Fréchet production possibility frontier.

Facts documented by Bilir (2014) using detailed firm-level data suggest that multinational firms are indeed a channel for international technology transfer: Intellectual property rights have a strong and positive effect on the location decision of multinational firms, and more so if they operate in sectors in which the scope for imitation is higher. Further evidence is provided in Bilir and Morales (2018). Using a long panel of U.S. multinational firms, from BEA, they document that innovation at the parent company substantially

\footnotetext{
${ }^{17}$ In their own words "A firm's technology capital is its unique know-how from investing in research and development, brands, and organization capital." The main characteristic of this capital is its non-rivalry.
} 
increases the efficiency of affiliates abroad: The average U.S. multinational firm realizes abroad over a quarter of the gains from innovation.

All these papers treat technology as non-rival within the firm. In contrast, Burstein and Monge-Naranjo (2007) focus on a scarce resource that cannot be easily replicated within the firm, managerial know-how, which, in turn, shapes the firm productivity. MP arises as the reallocation of managerial talent to foreign countries to gain control of foreign factors of production. They calculate output gains from removing barriers to managerial mobility of 12 percent. ${ }^{18}$

Next, we present a simplified version of the model in Ramondo and Rodríguez-Clare (2013). We abstract from non-tradable and intermediate tradable goods, an input-output structure, and the shipment of inputs from the Home country to the country of the affiliate. These are all important components to be taken into account when quantifying the model. Here, we just want to illustrate how MP can be incorporated into the canonical Ricardian model as a channel for technology diffusion.

The model inherits the main features of the EK Ricardian model of trade, but it is extended so that both trade and MP are two possible ways of reaching foreign consumers. As in models of "horizontal" FDI (e.g., Helpman et al., 2004) trade and MP are competing ways to serve a foreign market. Additionally, affiliates of multinational firms abroad can serve markets, other that the one of operations, through exports-i.e., export-platform FDI.

There are $N$ countries and a continuum of tradable goods produced under constant returns to scale with only labor. Knowledge transfers through MP take the following form. Firms in country $i$ have a technology to produce each good at home and in each foreign country. These technologies are described by the vector $\boldsymbol{A}_{i}(v) \equiv\left[A_{i 1}(v), \ldots, A_{i N}(v)\right]$. MP occurs when a country $i$ produces in another country $o \neq i$ with productivity $A_{i o}(v)$. If $A_{i o}(v)=0$ for all $o \neq i$, and for all $v \in[0,1]$, the model reverts to the EK model of trade in

\footnotetext{
${ }^{18}$ Based on Lucas (1978), Monge-Naranjo (2018) builds a dynamic OLG model in which foreign firms decide to locate in a foreign country and bring their know-how, while domestic firms decide how much to invest in know-how given the exposure to foreign know-how and the competition that foreign firms entail. Know-how comes from two sources: the firm-specific know-how embedded in its older workers that gets transmitted to the young ones; and the aggregate know-how from all the firms operating in the economy. Because of the presence of externalities, the model delivers the possibility that openness to foreign firms may lead to losses in income and welfare.
} 
Section 2.

The productivity vector $\boldsymbol{A}_{i}(v)$ for each good is a random variable drawn independently across goods and countries from the following distribution,

$$
\mathbb{P}\left[A_{i 1}(v) \leq a_{1}, \ldots, A_{i N}(v)\right]=\exp \left[-\left(\sum_{o} T_{i} a_{i o}^{-\theta /(1-\rho)}\right)^{1-\rho}\right]
$$

where $\theta>\max \{1, \sigma-1\}$ and $\rho \in[0,1)$. We call the distribution in (19) a symmetric multivariate $\theta$-Fréchet distribution for reasons that will become clear in the next section. ${ }^{19}$ The scale and shape parameters are, respectively, $T_{i}$ and $\theta$, and have the same interpretation as in the baseline trade model: Lower $\theta$ means more heterogeneous productivity draws and hence stronger comparative advantage forces; higher $T_{i}$ means better productivity draws on average for firms from $i$ producing anywhere. The parameter $\rho$ determines the degree of correlation among productivity draws in $\boldsymbol{A}_{i}(v)$ : If $\rho=0$, productivity draws are uncorrelated across production locations, while as $\rho \rightarrow 1$ productivity draws are perfectly correlated across locations of productions for a good $v$-i.e., $A_{i i}(v)=A_{i o}(v)$, for all $o$.

Assume that trade is subject to iceberg-type costs: $\tau_{o d} \geq 1$ units of any good must be shipped from country $o$ for one unit to arrive in country $d$, with $\tau_{d d}=1$ for all $d$ and $\tau_{o d} \leq \tau_{o k} \tau_{k d}$ for all $o, d, k$. Similarly, MP from country $i$ with production in $o$ incurs a productivity loss modeled as an iceberg-type bilateral MP cost, $\gamma_{i o} \geq 1$, with $\gamma_{o o}=1$, for all $i$. These costs are meant to capture the various costs of technology transfer incurred by multinational firms when they operate in a different production location other than their country of origin. Finally, following Head and Mayer (2018), we assume that MP from country $i$ selling in destination market $d$ incurs a loss also modeled as an iceberg-type bilateral cost, $\delta_{i d} \geq 1$, with $\delta_{d d}=1$. As they argue, this loss is meant to capture marketing costs incurred because the headquarter of the firm is different from the market where consumers are located. ${ }^{20}$

\footnotetext{
${ }^{19}$ See the Appendix in the working paper version of Ramondo and Rodríguez-Clare (2013) for an extension of Eaton and Kortum (2001) that generates a production possibility frontier that is has symmetric $\theta$-Fréchet form.

${ }^{20}$ Head and Mayer (2018) apply their model to the car industry. They argue that "current 'deep' integration agreements contain whole chapters that do not operate on the origin-destination path traversed by goods. Rather, topics such as harmonization of standards, protection of investments, and facilitation of temporary movement of professionals, mainly affect the flows of headquarters services to production
} 
The marginal cost of delivering good $v$ to destination $d$ produced in location $o$ with technologies originated in country $i$ is

$$
c_{i o d}(v)=\frac{c_{i o d}}{A_{i o}(v)},
$$

where $c_{i o d} \equiv W_{o} \tau_{o d} \gamma_{i o} \delta_{i d}$. Good $v$ is delivered to consumers in $d$ : through trade if $i=o \neq d$; through horizontal FDI if $i \neq o=d$; through export-platform FDI if $i \neq o \neq d$; and through vertical FDI if $i=d \neq o .{ }^{21}$ Domestic firms will be the ones serving market $d$ in good $v$ when $i=o=d$.

Under perfect competition, unit costs are equal to prices, and the lowest-cost producers will deliver good $v$ to market $d$,

$$
P_{d}(v)=\min _{o, i=1, \ldots, N} \frac{c_{i o d}}{A_{i o}(v)}
$$

Given that the symmetric $\theta$-Fréchet distribution has the max-stability property-for reasons that we explain in the next section-we can apply the same reasoning as for the EK model of trade and derive similar results.

The expenditure share on goods produced in $o$ for destination $d$ with technology from $i$ is

$$
\pi_{i o d}=\left(\frac{P_{i o d}}{P_{i d}}\right)^{-\frac{\theta}{1-\rho}}\left(\gamma \frac{P_{i d}}{P_{d}}\right)^{-\theta}
$$

where $P_{i o d} \equiv c_{i o d} T_{i}^{-1 / \theta}, P_{i d} \equiv\left(\sum_{o=1}^{N} P_{i o d}^{-\theta /(1-\rho)}\right)^{-\frac{1-\rho}{\theta}}$, and the price index in $d$ is

$$
P_{d}=\gamma\left(\sum_{i} P_{i d}^{-\theta}\right)^{-1 / \theta},
$$

where $\gamma \equiv \Gamma(1+(1-\sigma) / \theta)^{1 /(1-\sigma)}$ with $\Gamma(\cdot)$ the Gamma function. The first term on the righthand side of (22) is the share of expenditure that country $d$ allocates to goods produced with country $i$ 's technologies using labor in country $o$, while the second term is the share and distribution affiliates." Thus, these frictions, they argue, become key in evaluating the welfare gains of trade agreements such as NAFTA and the European Union.

${ }^{21}$ The last case can be thought as capturing "factory-less goods producing firms" described in Bernard and Fort (2015). 
of these goods produced everywhere.

The aggregate expenditure share on goods produced in $o$ for $d$-i.e., the bilateral trade share- is $\pi_{o d}^{T}=\sum_{i=1}^{N} \pi_{i o d}$, while the expenditure share on goods from $i$ produced in $o-$ i.e., the bilateral MP share-is $\pi_{i o}^{M}=\sum_{d=1}^{N} \pi_{i o d}$.

The question we ask is: How does trade and diffusion through MP interact to shape the gains from openness? Does trade complement or substitute diffusion forces that act through MP? Ramondo and Rodríguez-Clare (2013) define the concepts of substitution and complementarity through the relation between the implied gains from trade (MP) in the model with both flows, and the implied gains from trade (MP) implied by a model with only trade (MP). The gains from trade (MP) in the full model, denoted by GT (GMP), are given by the change in the real wage from a situation without trade (MP), but MP (trade), to a situation with both trade and MP. The gains from trade (MP) coming from a model with only trade (MP), denoted by $G T^{*}\left(G M P^{*}\right)$, are given by the change in the real wage from isolation to an equilibrium with only trade (MP) but in which trade (MP) flows are the same as in the model with both trade and MP (i.e., the observed flows). Then: If $G T>G T^{*}$, trade is MP complement; if $G T<G T^{*}$ trade is MP substitute; and if $G T=G T^{*}$ trade is MP independent. Analogously, if $G M P>G M P^{*}$, MP is trade complement; if $G M P<G M P^{*}$, MP is trade substitute; and if $G M P=G M P^{*}, \mathrm{MP}$ is trade independent.

Even the simplified model presented here delivers rich patterns of complementarity and substitutability between the two modes of openness. The key parameter is the parameter indicating correlation in productivity across production locations, $\rho$. As Ramondo and Rodríguez-Clare (2013) show, the special case of independence, $\rho=0$, is particularly illuminating.

First, when $\rho=0$, trade and MP shares collapse, respectively, to

$$
\pi_{o d}^{T}=\left(\tau_{o d} W_{o}\right)^{-\theta} \sum_{i=1}^{N} T_{i}\left(\gamma \frac{\gamma_{i o} \delta_{i d}}{P_{d}}\right)^{-\theta} \quad \text { and } \quad \pi_{i o}^{M}=T_{i}\left(\gamma_{i o} W_{o}\right)^{-\theta} \sum_{d=1}^{N}\left(\gamma \frac{\tau_{o d} \delta_{i d}}{P_{d}}\right)^{-\theta}
$$


Assuming that $\delta_{i d}=\widetilde{\delta}_{i} \times \widetilde{\delta}_{d}$, both trade and MP shares satisfy gravity equations,

$$
\pi_{o d}^{T}=-\theta \ln \tau_{o d}+E_{o}+I_{d} \quad \text { and } \quad \pi_{i o}^{M}=-\theta \ln \gamma_{i o}+S_{i}+L_{o}
$$

where $E_{o} \equiv-\theta \ln W_{o}+\ln \sum_{i=1}^{N} T_{i}\left(\gamma_{i o} \widetilde{\delta}_{i}\right)^{-\theta}, I_{d} \equiv-\theta \ln \widetilde{\delta}_{d}+\theta \ln P_{d} / \gamma, S_{i} \equiv \ln T_{i}-\theta \ln \widetilde{\delta}_{i}$, and $L_{o} \equiv-\theta \ln W_{o}-\theta \ln \sum_{d=1}^{N} \gamma \tau_{o d} \widetilde{\delta}_{d} / P_{d}$.

Second, under independence, the gains from trade are exactly equal to the gains from trade coming from a model with only trade as in Arkolakis et al. (2012),

$$
G T_{d}=\left(\pi_{d d}^{T}\right)^{-1 / \theta}
$$

and trade is MP independent. Independent productivity draws across production locations basically makes irrelevant the tradeoff between trade and MP as alternative ways of serving a foreign market. ${ }^{22} \mathrm{MP}$, however, is not trade independent. The gains from diffusion through MP for a country that it is already open to trade are given by

$$
G M P_{d}=\left(\pi_{n n}^{M}\right)^{-1 / \theta} \times\left(\frac{\pi_{d d}^{T}}{\pi_{d d}^{T,-M}}\right)^{-1 / \theta}
$$

where $\pi_{n n}^{T,-M}$ is the domestic trade share in the equilibrium with trade but not MP. Because the gains from MP coming from an MP-only model are given by the first term on the righthand side of (25), the expression in (25) implies that MP can be either trade substitute, trade complement, or trade independent. The size of trade costs, countries, and aggregate productivity interacts to shape the decision of serving markets through trade, MP, and export-platform MP, and determines the relation between $G M P$ and $G M P^{*}$.

For the case of $\rho>0$, Ramondo and Rodríguez-Clare (2013) provide special cases to illustrate the different forces that determine whether trade and MP are substitutes or complements of each other. For instance, they are able to show analytically that, with symmetric countries, substitution forces dominate: Trade is an MP substitute, $G T<G T^{*}$, and MP is a trade substitute, $G M P<G M P^{*}$. The calibrated version of their model, that matches

\footnotetext{
${ }^{22}$ Trade becomes MP complement as soon as one assumes that some inputs from the Home country are needed for production in the host country, and these inputs are sufficiently imperfect substitute of local inputs (see Proposition 4 in Ramondo and Rodríguez-Clare, 2013).
} 
the observed bilateral trade and MP data, implies that the gains from trade can be twice as high as the gains calculated in trade-only models, suggesting that diffusion of technologies through MP complements trade flows; in contrast, MP is a mild trade substitute. ${ }^{23}$

By now, there is an extensive literature that builds and quantifies models of trade and MP using static EK-type approaches. For instance, Alviarez (2018) extends the model in Ramondo and Rodríguez-Clare (2013) to many sectors and shows that the gains from MP are three times higher than in the model with one sector. Arkolakis et al. (2018) extend Ramondo and Rodríguez-Clare (2013) to allow for heterogeneous production firms á la Melitz and creation of firms through free entry-what they call innovation. They use their framework to quantify the gains and losses of globalization for innovation and production workers. Tintelnot (2017) incorporates fixed costs of production into a framework similar to Arkolakis et al. (2018). Solving a complex permutational problem, he calibrates the model and evaluates the role of fixed costs in generating export platforms and its consequences on the gains from MP. Fan (2017) extends Arkolakis et al. (2018) to further incorporate the possibility of offshore R\&D: Multinational firms born in a given country match with researchers around the world to develop new blueprints, and then engage in production-possible offshore-and exports. That is, in his framework, the Home country of a multinational firm can be different from the place where they decide to carry innovation, and in turn, different from the production sites and consumer markets. When he quantifies the model, he finds that R\&D offshore is an important channel shaping the gains from globalization. Finally, Sun (2018) uses the framework in Arkolakis et al. (2018) to add a firm's technology choice: MP not only implies the transfer of Hicks-neutral productivity, but also the transfer of technologies of (varying) factor intensity. In a model with both capital and labor as factors of production, he shows that MP, by coming from capital-abundant countries and transferring capital-intensive technologies to its host countries, changes the aggregate demand of capital relative to labor, and hence, contributes to the decline in the labor share observed in several countries.

Two common themes in all these papers are that MP is a channel for international technology diffusion and that the modeling strategy is based on the EK Ricardian model of

\footnotetext{
${ }^{23}$ Their calibrated model includes tradable intermediate goods, non-tradable final goods, an inputoutput structure, and the shipment of inputs from the Home country to the affiliate.
} 
trade with a Fréchet productivity distribution. By having flexible general equilibrium models that capture the rich heterogeneity of the data, all these papers are able to draw quantitative conclusions, through counterfactual exercises, on the effects of MP on their host and Home countries, and they are able to evaluate the mechanisms through which technology transfer operates.

\section{New Directions for the Ricardian Model of Trade}

The EK model of trade assumes that productivities are independent Fréchet random variables across countries with a common shape. This assumption is restrictive in several ways: First, it does not allow for spatial correlation in technology, as the empirical evidence seems to suggest (Comin et al., 2013; Keller and Yeaple, 2013); second, as pointed out by Arkolakis et al. (2012), it restricts trade shares to the CES class, generating symmetric substitution patterns (i.e., a change in unit costs has the same effect on the aggregate price index of the importer regardless of the identity of the exporter); and finally, it does not include non-CES extensions of the EK model of trade (e.g., many sectors, multinational production, global value chains). The appeal of this assumption, however, has been that it generates max-stability-the distribution of the maximum is the same up to scale-which, in turn, is the key property that makes the EK model tractable.

Lind and Ramondo (2018) generalize the distribution of productivities in EK to a multivariate $\theta$-Fréchet distribution, allowing for an arbitrary spatial correlation structure of productivity while maintaining the key max-stability property necessary for tractability of the EK Ricardian model. This generalization also encompasses various extensions of the EK model in the literature to non-CES setups. Moreover, it naturally links to the models of innovation and diffusion in Section 3. ${ }^{24}$

\footnotetext{
${ }^{24}$ The framework in Lind and Ramondo (2018) falls under the very general class of Ricardian models analyzed by Adao et al. (2017) --one in which the factor demand system is invertible.
} 


\subsection{Productivity as a max-stable multivariate Fréchet random variable}

Definition 1 (Multivariate $\theta$-Fréchet distribution). A random vector, $\left(A_{1}, \ldots, A_{K}\right)$, has a multivariate $\theta$-Fréchet distribution if for any $\alpha_{k} \geq 0$ with $k=1, \ldots, K$ the random variable $\max _{k=1, \ldots, K} \alpha_{k} A_{k}$ has a Fréchet distribution with shape parameter $\theta$. In this case, the marginal distributions are Fréchet with (common) shape parameter $\theta$ and, for each $k=1, \ldots, K$, satisfy

$$
\mathbb{P}\left[A_{k} \leq a\right]=\exp \left[-T_{k} a^{-\theta}\right],
$$

for some scale parameter $T_{k}$.

This definition implies that a multivariate $\theta$-Fréchet distribution is max stable-up to scale the distribution of the max is the same as the distribution of the marginals. It includes as special cases the distribution in EK which is independent $\theta$-Fréchet, and the symmetric $\theta$-Fréchet distribution in Ramondo and Rodríguez-Clare (2013).

The class of multivariate $\theta$-Fréchet random variables puts minimal restrictions on dependence, but maintains the property of max stability. The restriction to a common shape is necessary for that property; general multivariate Fréchet distributions may have marginal distributions with different shape parameters, in which case the maximum, even under independence, is not distributed Fréchet.

The joint distribution of a multivariate $\theta$-Fréchet random variable can be characterized with a correlation function, $G: \mathbb{R}_{+}^{K} \rightarrow \mathbb{R}_{+}$. This function is closely related to a max-stable copula and to the social surplus function in GEV discrete choice models (McFadden, 1978). As such, the $G$-function must satisfy three restrictions: homogeneity of degree one; unboundedness; and differentiability. ${ }^{25}$ We add a normalization restriction to the correlation function, $G(0, \ldots, 0,1,0, \ldots, 0)=1$, that allows us to distinguish between absolute advantage — captured by scale parameters—and comparative advantage—captured by a correlation function.

\footnotetext{
${ }^{25}$ Homogeneity: for any $\lambda \geq 0 G\left(\lambda x_{1}, \ldots, \lambda x_{K}\right)=\lambda G\left(x_{1}, \ldots, x_{K}\right)$. Unboundedness: $G\left(x_{1}, \ldots, x_{K}\right) \rightarrow$ $\infty$ as $x_{k} \rightarrow \infty$ for any $k=1, \ldots, K$. Differentiability: The mixed partial derivatives of $G$ exist and are continuous up to order $K$. The $k^{\prime}$ th partial derivative of $G$ with respect to $k$ distinct arguments is nonnegative if $k$ is odd and non-positive if $k$ is even.
} 
The joint distribution of any multivariate $\theta$-Fréchet random variable can be parameterized in terms of the scale parameters of its marginal distributions and a correlation function,

$$
\mathbb{P}\left[A_{k} \leq a_{k}, \quad k=1, \ldots, K\right]=\exp \left[-G\left(T_{1} a_{1}^{-\theta}, \ldots, T_{K} a_{K}^{-\theta}\right)\right]
$$

The restrictions defining a correlation function ensure that (27) characterizes a valid multivariate Type II extreme value (Fréchet) distribution. Importantly, the homogeneity property of the correlation function implies the max-stability property: the maximum is Fréchet,

$$
\mathbb{P}\left[\max _{k=1, \ldots, K} A_{k} \leq a\right]=\exp \left[-G\left(T_{1}, \ldots, T_{K}\right) a^{-\theta}\right],
$$

with scale parameter $G\left(T_{1}, \ldots, T_{K}\right)$ and shape parameter $\theta$. The correlation function acts as an aggregator, returning the scale parameter of the maximum when evaluated at the scale parameters of the marginal distributions.

Correlation functions reflect comparative advantage because they measure relative productivity levels across varieties and across origin countries within the same destination market. Comparing the case of independence in (5) with (28), it is clear that the EK model in Section 2 has an additive correlation function. But an additive correlation function imposes a strong assumption, namely that comparative advantages across countries are symmetric. By allowing for heterogeneity in correlation, this generalization of the EK model allows for heterogeneity in comparative advantage.

As mentioned in previous sections, max-stability implies that the conditional and unconditional distributions of the maximum are identical. This property, as in EK, ensures tractability because it ensures that expenditure shares simply reflect the probability of importing from an origin country.

We ask next: What are the implications for trade shares and the gains from trade of using a multivariate $\theta$-Fréchet distribution with arbitrary correlation across exporters? 


\subsubsection{Trade shares}

The joint distribution of productivity determines the joint distribution of potential import prices into market $d$,

$$
\mathbb{P}\left[P_{1 d}(v) \geq p_{1}, \ldots, P_{N d}(v) \geq p_{N}\right]=\exp \left[-G^{d}\left(T_{1 d} W_{1}^{-\theta} p_{1}^{\theta}, \ldots, T_{N d} W_{N}^{-\theta} p_{N}^{\theta}\right)\right]
$$

Given the distribution of potential import prices, a country imports each variety from the cheapest source. As for the Ricardian model under independence in Section 2, the max-stability property, together with the previous characterization of the potential import price distribution, leads to closed-form results for trade shares and the price index, respectively,

$$
\pi_{o d}=\frac{P_{o d}^{-\theta} G_{o}^{d}\left(P_{1 d}^{-\theta}, \ldots, P_{N d}^{-\theta}\right)}{G^{d}\left(P_{1 d}^{-\theta}, \ldots, P_{N d}^{-\theta}\right)} \equiv \pi_{o d}^{\mathrm{GEV}}\left(\mathbf{P}_{d}, X_{d}\right)
$$

where $P_{o d} \equiv T_{o d}^{-1 / \theta} W_{o}, \mathbf{P}_{d}=\left[P_{1 d}, \ldots, P_{N d}\right], X_{d}$ is total expenditure in country $d$,

$$
G_{o}^{d}\left(x_{1}, \ldots, x_{N}\right) \equiv \frac{\partial G^{d}\left(x_{1}, \ldots, x_{N}\right)}{\partial x_{o}}
$$

and

$$
P_{d}=\gamma G^{d}\left(P_{1 d}^{-\theta}, \ldots, P_{N d}^{-\theta}\right)^{-\frac{1}{\theta}}
$$

with $\gamma \equiv \Gamma\left(\frac{\theta-\sigma}{\theta}\right)^{-\frac{1}{\sigma}}$ and $\Gamma(\cdot)$ the Gamma function.

The formula for the expenditure share in (29) takes the same form as choice probabilities in generalized extreme value (GEV) discrete choice models (McFadden, 1978), with the import price index taking the place of choice-specific utility. Accordingly, we refer to the implied import demand system, $\pi_{o d}^{\mathrm{GEV}}$, as a GEV import demand system. In turn, the price level in each destination market is determined by the correlation function, $G^{d}$, which can be interpreted as an aggregator that defines the welfare-relevant price index. In analogy to the discrete choice literature, welfare calculations depend crucially on the specification of this function.

The direct consequence of this result is that a Ricardian model with a multivariate $\theta$ Fréchet productivity distribution as in (27) is equivalent to any model that generates a 
generalized extreme value (GEV) import demand system as in (29). ${ }^{26}$ Since expenditure shares do not depend on overall expenditure, the GEV class is homothetic, features the gross substitutability property, and belongs to the large class of invertible demand systems.

An important class of models within the GEV class is the CES model. This model is generated by an additive correlation function, $G^{d}\left(x_{1}, \ldots, x_{N}\right)=\sum_{o=1}^{N} x_{o}$, and entails expenditure shares of the form

$$
\pi_{o d}=\frac{P_{o d}^{-\theta}}{\sum_{o^{\prime}=1}^{N} P_{o^{\prime} d}^{-\theta}} \equiv \pi_{o d}^{\mathrm{CES}}\left(\mathbf{P}_{d}, X_{d}\right)
$$

The GEV class, however, is much larger than the CES class and accommodates many non-CES Ricardian trade models commonly used in the literature. ${ }^{27}$

The MP model in the previous section and the multi-sector EK model in Caliendo and Parro (2015) belong to the GEV class. They are generated by a correlation function that takes a cross-nested CES form,

$$
G^{d}\left(x_{1}, \ldots, x_{N}\right)=\sum_{m=1}^{M}\left(\sum_{o=1}^{N}\left(\omega_{m o d} x_{o}\right)^{1 /\left(1-\rho_{m}\right)}\right)^{1-\rho_{m}}
$$

where $\omega_{m o d} \equiv T_{m o d} / T_{o d}$, with $T_{o d}=\sum_{m^{\prime}=1}^{M} T_{m^{\prime} o d}$, and $m$ refers to the country of origin of MP and to sectors, alternately. The import demand system implied by this correlation function is

$$
\pi_{o d}=\sum_{m=1}^{M}\left(\frac{P_{m o d}}{P_{m d}}\right)^{-\frac{\theta}{1-\rho_{m}}} \frac{P_{m d}^{-\theta}}{\sum_{m^{\prime}=1}^{M} P_{m^{\prime} d}^{-\theta}},
$$

where $P_{m o d} \equiv W_{o} T_{m o d}^{-1 / \theta}$, and $P_{m d} \equiv\left(\sum_{o=1}^{N} P_{m o d}^{-\frac{\theta}{1-\rho_{m}}}\right)^{-\frac{1-\rho_{m}}{\theta}}$. The model in Ramondo and Rodríguez-Clare (2013) presented in the previous section is obtained by setting $\rho_{m}=\rho$, for all $m$, while Caliendo and Parro (2015) is obtained as the limiting case as $\theta \rightarrow 0 .{ }^{28}$

\footnotetext{
${ }^{26}$ In a recent paper, Lashkaripour and Lugovskyy (2017) use a nested Fréchet in the context of the EK model of trade, with nests representing firm-specific quality. Their setup also belongs to the GEV class.

27 Multi-sector models (Costinot et al., 2012; Costinot and Rodrìguez-Clare, 2014; Caliendo and Parro, 2015; Ossa, 2015; Levchenko and Zhang, 2016; French, 2016); multinational production models (Ramondo and Rodríguez-Clare, 2013); global value chains models (Antràs and de Gortari, 2017); and models of trade with domestic geography (Fajgelbaum and Redding, 2014; Ramondo et al., 2016; Redding, 2016).

${ }^{28}$ With $\theta \rightarrow 0$, the expenditure shares across sectors are Cobb-Douglas. More generally, French (2016)
} 
One can go a step further and, adapting results from the discrete choice literature, show that the set of import demand systems generated by any Ricardian model can be approximated arbitrarily well by the GEV class. This result in Lind and Ramondo (2018) implies that any import demand system generated by the Ricardian trade model can be approximated by a Ricardian trade model where productivity has a multivariate $\theta$-Fréchet distribution.

\subsubsection{Gains from trade}

As for the EK model under independence, we can easily calculate the gains from trade stemming from the GEV import demand system. The calculation entails a simple correction to the formula for gains in Arkolakis et al. (2012). Using a multivariate $\theta$-Fréchet distribution with correlation across exporters adds, however, an important channel for the gains from trade: Countries gain more if they trade with partners that have more dissimilar technologies. The implied GEV import demand system allows for richer patterns of substitution across exporters than CES: By having $\partial G^{d}\left(x_{1}, \ldots, x_{N}\right) / \partial x_{o} \neq G^{d}\left(x_{1}, \ldots, x_{N}\right) / \partial x_{o^{\prime}}$, for $o \neq o^{\prime}$, the effect of a change in the unit cost on the aggregate importer price index can vary substantially depending on the exporter.

Evaluating (29) for the domestic pair, and using (30) for the price index, we get

$$
\pi_{d d}=T_{d d}^{-1 / \theta} W_{d}^{-\theta}\left(\gamma \frac{G_{d}^{d}\left(P_{1 d}^{-\theta}, \ldots, P_{N d}^{-\theta}\right.}{P_{d}}\right)^{-\theta}
$$

Solving for the real wage yields

$$
\frac{W_{d}}{P_{d}}=\gamma^{-1} T_{d d}^{1 / \theta}\left(\frac{\pi_{d d}}{G_{d d}}\right)^{-1 / \theta}
$$

where $G_{d d} \equiv G_{d}^{d}\left(P_{1 d}^{-\theta}, \ldots, P_{N d}^{-\theta}\right)$. Under autarky, $G_{d d}=\pi_{d d}=1$. Hence, the gains from uses a CES aggregator across sectors, but he restricts the elasticities of substitution for each sector to be the same, $\rho_{m}=\rho$, for all $m$. 
trade from autarky are given by

$$
G T_{d}=\left(\frac{\pi_{d d}}{G_{d d}}\right)^{-1 / \theta}
$$

For CES, $G_{d d}=1$ and we are back to the formula from the gains from trade in Arkolakis et al. (2012) — presented in (14) — that only depends on the self-trade share of a country. For GEV, countries with the same self-trade share can have very different gains depending on the way their technology is correlated with their trading partners. ${ }^{29}$

Next, we show how a multivariate $\theta$-Fréchet distribution with arbitrary correlation function can be generated from an innovation and adoption process.

\subsection{Generating max-stable multivariate Fréchet distributions}

We next present a structure for technology that is necessary and sufficient for productivity to be distributed multivariate $\theta$-Fréchet. Lind and Ramondo (2018) assume that technologies are a product of global innovations and a country's production possibility frontier is the result of adopting those global innovations according to the country's ability to apply them. The equivalence between this structure of technology and multivariate $\theta$-Fréchet productivity is a consequence of the spectral representation theorem for max-stable processes (De Haan, 1984; Penrose, 1992; Schlather, 2002). In contrast to the results in Section 3 , in which a independent $\theta$-Fréchet productivity distribution was obtained asymptotically, the result presented below is exact and for a $\theta$-Fréchet distribution with arbitrary correlation patterns.

Lind and Ramondo (2018) establish that productivity, $\left\{A_{o d}(v)\right\}_{o=1}^{N}$, is multivariate $\theta$-Fréchet if and only if it satisfies the following three assumptions-which they refer to as a global innovation representation.

Assumption 5 (Innovation Decomposition). For each $v$, there exists a countable set of global innovations, $i=1,2, \ldots$, with global productivity $\left\{Z_{i}(v)\right\}_{i=1,2, \ldots}$ and spatial applicability

\footnotetext{
${ }^{29}$ Lind and Ramondo (2018) show that, given the correlation function $G^{d}$, observed trade shares are sufficient to calculate $G_{d d}$. In this way, the adjustment entailed by GEV is not more demanding in terms of estimation than CES.
} 
$\left\{\left\{A_{\text {iod }}(v)\right\}_{o=1}^{N}\right\}_{i=1,2, \ldots}$ such that

$$
A_{o d}(v)=\max _{i=1,2, \ldots} Z_{i}(v) A_{i o d}(v) .
$$

Assumption 6 (Independence). $\left\{\left\{A_{i o d}(v)\right\}_{o=1}^{N}\right\}_{i=1,2, \ldots}$ is independent of $\left\{Z_{i}(v)\right\}_{i=1,2, \ldots}$ and i.i.d. over $(i, v)$.

Assumption 7 (Poisson Innovations). There exists $\theta>0$ such that the collection $\left\{Z_{i}(v)^{\theta}\right\}_{i=1,2, \ldots}$ consists of the points of a Poisson process with intensity measure $z^{-2} d z$, and i.i.d. over $v$.

Assumption 5 states that countries adopt the best innovation (i.e., a blueprint) when producing goods taking as given the spatial applicability of individual innovations. For a given good $v$, each innovation $i$ has a global productivity component, $Z_{i}(v)$, and an origin-destination specific spatial applicability component, $A_{i o d}(v)$. The global productivity component measures the fundamental efficiency of the production technique $i$ and is identical across all origins and destinations. In turn, the spatial applicability component captures origin-destination specific factors that determine the efficiency of the technique when adopted at origin $o$ to deliver goods to destination $d$.

The key aspect of Assumption 6 is that it does not impose independence of applicability across origin countries; instead, it allows for arbitrary patterns of spatial correlation. Moreover, the assumption does not impose any particular probability distribution of applicability; this distribution can belong to any family.

Finally, Assumption 7 states that the global productivity component, $Z_{i}(v)$, follows a non-homogenous Poisson process over $i$ 's, for each $v$. This assumption implies that the distribution of $Z_{i}(v)$ over $v$, conditional on $i$, is Pareto with shape parameter $\theta \times$ $i$ : Loosely speaking, better innovations-i.e., with higher global productivity-are less likely to be observed, but conditional on being observed, they have a fatter-tailed-and lower-variance-Pareto distribution across goods $v$.

This characterization establishes that $\theta$-Fréchet-distributed productivity can always be interpreted as arising from the adoption of technologies and that patterns of adoption depend on the ability of exporters to apply innovations. It also establishes a method to compute the scale parameters (absolute advantage) and correlation functions (com- 
parative advantage) of multivariate $\theta$-Fréchet random variables as moments of spatial applicability ${ }^{30}$,

$$
T_{\text {od }} \equiv \mathbb{E} A_{\text {iod }}(v)^{\theta} \quad \text { and } \quad G^{d}\left(x_{1}, \ldots, x_{N}\right) \equiv \mathbb{E} \max _{o=1, \ldots, N} \frac{A_{\text {iod }}(v)^{\theta}}{T_{\text {od }}} x_{o}, \text { for all } o=1, \ldots, N
$$

For example, assume that the applicability of individual technologies follows a multivariate $\theta$-Fréchet distribution across origin countries with symmetric correlation, as in our model of MP above. Then, the joint distribution of applicability is

$$
\mathbb{P}\left[A_{i 1 d}(v) \leq a_{1}, \ldots, A_{i N d}(v) \leq a_{N}\right]=\exp \left[-\left(\sum_{o=1}^{N}\left(T_{o d} a_{o}^{-\theta}\right)^{\frac{1}{1-\rho}}\right)^{1-\rho}\right]
$$

where each $T_{o d}$ is an origin-destination specific scale parameter and $0 \leq \rho<1$ parameterizes the correlation in applicability across origin countries. We can compute the correlation function for this example using the max-stability property of multivariate Fréchet distributions in (28). ${ }^{31}$ The correlation function takes the form of a CES aggregator with the correlation parameter $\rho$ determining the elasticity of substitution across origins; when $\rho=0$, the correlation function is additive, as in EK, and draws are uncorrelated across origins.

The important question left for future research is how the global innovation representation connects to the dynamic models in Section 3 that obtain Fréchet production possibility frontiers as a result of an innovation and knowledge diffusion process (Eaton and Kortum, 1999, 2001; Buera and Oberfield, 2016).

\footnotetext{
${ }^{30}$ Since the copula of the joint distribution is related to its correlation function, this result also gives a method to construct max-stable copulas.

${ }^{31}$ Specifically, for any given vector $\left(a_{1}, \ldots, a_{N}\right)$, the random variable $\max _{o=1, \ldots, N} A_{\text {iod }}(v) / a_{o}$ must be $\theta$ Fréchet with scale $\left(\sum_{o=1}^{N}\left(T_{o d} a_{o}^{-\theta}\right)^{1 /(1-\rho)}\right)^{1-\rho}$. Since the $\theta$-moment of a $\theta$-Fréchet random variable is given by its scale parameter, the correlation function is $G^{d}\left(x_{1}, \ldots, x_{N}\right)=\left(\sum_{o=1}^{N} x_{o}^{\frac{1}{1-\rho}}\right)^{1-\rho}$.
} 


\section{Conclusions}

There have been recent advances in the international trade literature on modeling knowledge creation and international technology diffusion, as well as their links with international flows of goods, services, and firms. This paper reviews the literature on innovation and knowledge diffusion built on a common methodological theme: Fréchet productivity distributions. The central pieces of our analysis are the model of innovation in Kortum (1997) and the Ricardian model of trade in Eaton and Kortum (2002). As such, all the models reviewed are quantitative general equilibrium models suitable for performing counterfactual analysis. We focus on the implications of the models regarding the gainsfrom-trade counterfactual and how they fit into the sufficient-statistic approach proposed in Arkolakis et al. (2012).

\section{References}

Adao, R., A. Costinot, and D. Donaldson (2017). Nonparametric counterfactual predictions in neoclassical models of international trade. The American Economic Review 107(3), 633-689.

Ades, A. and E. L. Glaeser (1999). Evidence on growth, increasing returns, and the extent of the market. The Quarterly Journal of Economics 114(3), 1025-1045.

Alcala, F. and A. Ciccone (2004). Trade and productivity. The Quarterly Journal of Economics 119(2), 613-646.

Alesina, A., E. Spolaore, and R. Wacziarg (2000). Economic integration and political disintegration. American Economic Review 90(5), 1276-1296.

Alfaro, L. and M. X. Chen (2018). Selection and market reallocation: Productivity gains from multinational production. American Economic Journal: Economic Policy 10(2), 1-38.

Alvarez, F. E., F. J. Buera, and R. E. Lucas (2008). Models of idea flows. NBER Working Paper Series (14135).

Alvarez, F. E., F. J. Buera, and R. E. Lucas (2014). Idea flows, economic growth, and trade. NBER Working Paper Series (19667).

Alviarez, V. (2018). Multinational production and comparative advantage. Manuscript $U B C$. 
Antràs, P. and A. de Gortari (2017). On the geography of global value chains. Mimeo, Harvard University.

Antrás, P. and S. R. Yeaple (2014). Multinational firms and the structure of international trade. Handbook of International Economics 4, 55-130.

Arkolakis, C., A. Costinot, and A. Rodríguez-clare (2012). New trade models, same old gains? The American Economic Review, 94-130.

Arkolakis, C., S. Demidova, P. J. Klenow, and A. Rodríguez-Clare (2008). Endogenous variety and the gains from trade. American Economic Review, Papers and Proceedings 98(4), $444-450$.

Arkolakis, C., N. Ramondo, A. Rodríguez-Clare, and S. Yeaple (2018). Innovation and production in the global economy. American Economic Review Forthcoming.

Atkeson, A. and A. Burstein (2010). Innovation, firm dynamics, and international trade. Journal of Political Economy 118(3), 433-489.

Benhabib, J., J. Perla, and C. Tonetti (2017). Reconciling models of diffusion and innovation: A theory of the productivity distribution and technology frontier. Unpublished.

Bernard, A. B., J. Eaton, J. B. Jensen, and S. Kortum (2003). Plants and productivity in international trade. The American Economic Review 93(4), 1268-1290.

Bernard, A. B. and T. C. Fort (2015). Factory-less goods producing firms. American Economic Review Papers and Proceedings 105, 518-23.

Bilir, K. and E. Morales (2018). Innovation in the global firm. Mimeo, Princeton University.

Bilir, L. K. (2014). Patent laws, product life-cycle lengths, and multinational activity. American Economic Review 104(7), 1979Đ2013.

Buera, F. J. and E. Oberfield (2016). The global diffusion of ideas. National Bureau of Economic Research.

Burstein, A. and A. Monge-Naranjo (2007). Foreign know-how, firm control, and the income of developing countries. The Quarterly Journal of Economics 124(1), 149-195.

Caliendo, L. and F. Parro (2015). Estimates of the trade and welfare effects of nafta. The Review of Economic Studies 82(1), 1-44.

Comin, D., M. Dmitriev, and E. Rossi-Hansberg (2013). The spatial diffusion of technology. Unpublished.

Comin, D. and B. Hobijn (2004). Cross-country technology adoption: making the theories face the facts. Journal of Monetary Economics 51, $39 Đ 83$.

Comin, D. and B. Hobijn (2010). An exploration of technology diffusion. American Economic Review 100, $2031 Đ 2059$. 
Comin, D. and M. Mestieri (2018). If technology has arrived everywhere, why has income diverged? American Economic Journal forthcoming.

Costinot, A., D. Donaldson, and I. Komunjer (2012). What goods do countries trade? a quantitative exploration of ricardo's ideas. Review of Economic Studies 79, 581-608.

Costinot, A. and A. Rodrìguez-Clare (2014). Trade theory with numbers: Quantifying the consequences of globalization. Technical Report 4.

De Haan, L. (1984). A spectral representation for max-stable processes. The Annals of Probability 12(4), 1194-1204.

de Haan, L. and A. Ferreira (2006). Extreme Value Theory: An Introduction. Springer Series in Operations Research and Financial Engineering. Springer New York.

Donaldson, D. (2015). The gains from market integration. Annual Review of Economics 7, $619-47$.

Eaton, J. and S. Kortum (1996). Trade in ideas patenting and productivity in the oecd. Journal of International Economics 40(3), $251 Đ 278$.

Eaton, J. and S. Kortum (1999). International technology diffusion: Theory and measurement. International Economic Review 40(3), 537-570.

Eaton, J. and S. Kortum (2001). Technology, trade, and growth: A unified framework. European Economic Review 45, 742-755.

Eaton, J. and S. Kortum (2002). Technology, geography, and trade. Econometrica, 17411779.

Eeckhout, J. and B. Jovanovic (2002). Knowledge spillovers and inequality. The American Economic Review 92(5), 1290-1307.

Fajgelbaum, P. and S. Redding (2014). External integration, structural transformation and economic development: Evidence from argentina 1870-1914. NBER Working Paper 20217.

Fan, J. (2017). Talent, geography, and offshore r\&d. Mimeo, Penn State University.

Feyrer, J. (2009). Distance, trade, and income-the 1967 to 1975 closing of the suez canal as a natural experiment. NBER Working Paper Series 15557.

Frankel, J. and D. Romer (1999). Does trade cause growth? American Economic Review 89(3), 379-399.

French, S. (2016). The composition of trade flows and the aggregate effects of trade barriers. Journal of International Economics 98, 114-137.

Harrison, A. and A. Rodríguez-Clare (2010). Trade, foreign investment, and industrial policy. Handbook of Development Economics, D. Rodrik and M. Rosenzweig, eds. 5, 40404214. 
Head, K. and T. Mayer (2018). Brands in motion: How frictions shape multinational production. CEPR DP 10797.

Helpman, E., M. J. Melitz, and S. R. Yeaple (2004). Exports versus fdi with heterogeneous firms. American Economic Review 94(1), 300-316.

Irarrazabal, A., A. Moxnes, and L. D. Opromolla (2013). The margins of multinational production and the role of intra-firm trade. Journal of Political Economy 121(1), 74-126.

Javorcik, B. (2004). Does foreign direct investment increase the productivity of domestic firms? in search of spillovers through backward linkages. American Economic Review 94(3), 605-627.

Jones, C. (1995). R\&d-based models of economic growth. Journal of Political Economy 103(4), 759-84.

Jones, C. (2005). Growth and ideas. Handbook of Economic Growth, P. Aghion and S. Durlauf, eds. 1A, 1064-1108.

Jovanovic, B. and G. M. McDonald (1994). Competitive diffusion. Journal of Political Economy 102, 24-52.

Jovanovic, B. and R. Rob (1989). The growth and diffusion of knowledge. Review of Economic Studies 56, 569-582.

Keller, W. (2004). International technology diffusion. Journal of Economic Literature 42, 752-782.

Keller, W. (2010). International trade, foreign direct investment, and technology spillovers. Handbook of the Economics of Innovation 2, 793-829.

Keller, W. and S. R. Yeaple (2013). The gravity of knowledge. American Economic Review 103(4), 1414.

Kortum, S. (1997). Research, patenting, and technological change. Econometrica 65(6).

Lashkaripour, A. and V. Lugovskyy (2017). Industry-level scale economies: from microestimation to macro-implications. Mimeo, Indiana University.

Levchenko, A. and J. Zhang (2016). The evolution of comparative advantage: Measurement and welfare implications. Journal of Monetary Economics 78, 96-111.

Lind, N. and N. Ramondo (2018). Trade with correlation. NBER Working Paper Series (24380).

Lucas, R. E. (1978). On the size distribution of business firms. The Bell Journal of Economics.

Lucas, R. E. (2009). Ideas and growth. Economica 76(301), 1-19.

Lucas, R. E. and B. Moll (2014). Knowledge growth and the allocation of time. Journal of Political Economy 122(1), 1-51. 
Luttmer, E. (2012). Eventually, noise and imitation implies balanced growth. Federal Reserve Bank of Minneapolis Working Paper (699).

Markusen, J. (1984). Multinationals, multi-plant economies, and the gains from trade. Journal of International Economics 16, 205-226.

McFadden, D. (1978). Modeling the choice of residential location. Transportation Research Record (673).

McGrattan, E. R. and E. C. Prescott (2009). Openness, technology capital, and development. Journal of Economic Theory 144(6), 2454-2476.

Monge-Naranjo, A. (2018). Markets, externalities, and the dynamic gains of openness. International Economic Review forthcoming.

Ossa, R. (2015). Why trade matters after all. Journal of International Economics 97(2), 266277.

Pavcnik, N. (2002). Trade liberalization, exit, and productivity improvements: Evidence from chilean plants. The Review of Economic Studies 69, 245-76.

Penrose, M. D. (1992). Semi-min-stable processes. The Annals of Probability 20(3), 14501463.

Perla, J. and C. Tonetti (2014). Equilibrium imitation and growth. Journal of Political Economy $122,512-76$.

Perla, J., C. Tonetti, and M. Waugh (2015). Equilibrium technology diffusion, trade, and growth. Unpublished.

Ramondo, N. (2009). Foreign plants and industry productivity: Evidence from chile. Scandinavian Journal of Economics 111(4), 789Đ809.

Ramondo, N. (2014). A quantitative approach to multinational production. Journal of international economics 93, 108-122.

Ramondo, N. and A. Rodríguez-Clare (2010). Growth, size, and openness: A quantitative approach. American Economic Review Papers and Proceedings 100(2), 62-67.

Ramondo, N. and A. Rodríguez-Clare (2013). Trade, multinational production, and the gains from openness. Journal of Political Economy 121(2), 273-322.

Ramondo, N., A. Rodríguez-Clare, and M. Saborío-Rodríguez (2016). Trade, domestic frictions, and scale effects. American Economic Review 106(10), 3159-84.

Redding, S. (2016). Goods trade, factor mobility and welfare. Journal of International Economics 101, 148-167.

Rodríguez-Clare, A. (2007). Trade, diffusion, and the gains from openness. Unpublished.

Sachs, J. D. and A. Warner (1995). Economic reform and the process of global integration. Brookings Papers on Economic Activity 1. 
Sampson, T. (2016). Dynamic selection: An idea flows theory of entry, trade and growth. The Quarterly Journal of Economics 131(1), 315-380.

Schlather, M. (2002). Models for stationary max-stable random fields. Extremes 5(1), 33-44.

Shikher, S. (2012). International production, technology diffusion, and trade. Journal of International Trade and Economic Development 23(1), 111-154.

Somale, M. (2018). Comparative advantage in innovation and production. Unpublished.

Sun, C. (2018). Factor-biased multinational production and the labor share. Unpublished.

Tintelnot, F. (2017). Global production with export platforms. Quarterly Journal of Economics 132(1), 157-209.

UNCTAD (2005). Transnational corporations and the internationalization of r\&d. World Investment Report.

UNCTAD (2017). Investment and the digital economy. World Investment Report. 